Provided for non-commercial research and education use. Not for reproduction, distribution or commercial use.

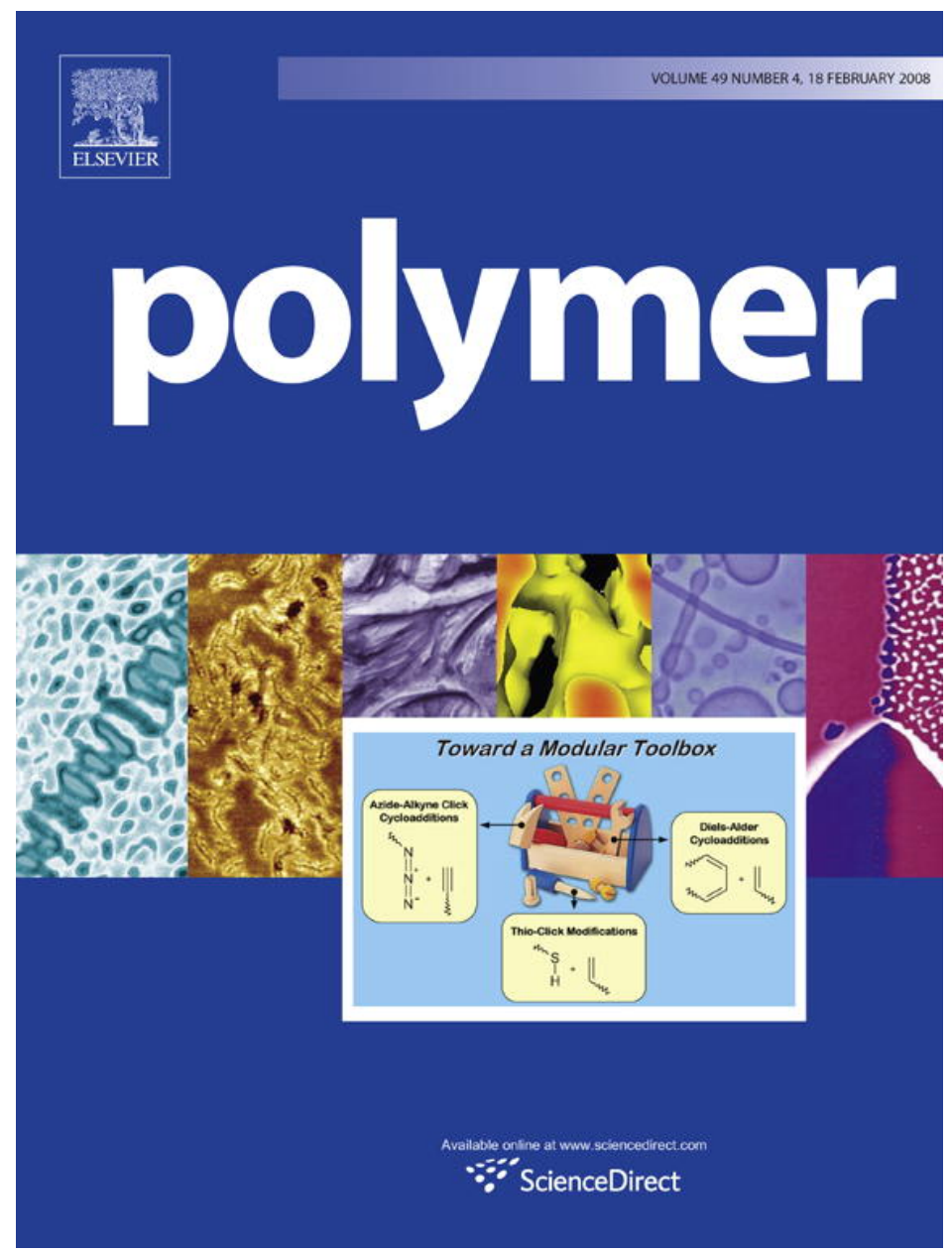

This article was published in an Elsevier journal. The attached copy

is furnished to the author for non-commercial research and education use, including for instruction at the author's institution, sharing with colleagues and providing to institution administration.

Other uses, including reproduction and distribution, or selling or licensing copies, or posting to personal, institutional or third party websites are prohibited.

In most cases authors are permitted to post their version of the article (e.g. in Word or Tex form) to their personal website or institutional repository. Authors requiring further information regarding Elsevier's archiving and manuscript policies are encouraged to visit: 


\title{
Recrystallization studies on isotropic cold-crystallized PET: Influence of heating rate
}

\author{
A. Flores ${ }^{\text {a }}$, M. Pieruccini ${ }^{\mathrm{b}}$, U. Nöchel ${ }^{\mathrm{c}}$, N. Stribeck ${ }^{\mathrm{c}}$, F.J. Baltá Calleja ${ }^{\text {a,* }}$ \\ a Instituto de Estructura de la Materia, Macromolecular Physics, CSIC, Serrano 119, 28006 Madrid, Spain \\ ${ }^{\mathrm{b}}$ CNR, Istituto per i Processi Chimico-Fisici Sez. Messina, Via La Farina 237, I-98123 Messina, Italy \\ ${ }^{\mathrm{c}}$ Institut für Technische und Makromolekulare Chemie, Universität Hamburg, Hamburg, Germany
}

Received 19 November 2007; received in revised form 14 December 2007; accepted 28 December 2007

Available online 6 January 2008

\begin{abstract}
The nanostructural changes associated to the multiple melting behaviour of isotropic cold-crystallized poly(ethylene terephthalate) (PET) have been investigated by means of simultaneous wide- and small-angle X-ray scattering, using a synchrotron radiation source. Variations in the degree of crystallinity, coherent lateral crystal size and long period values, as a function of temperature, for two different heating rates are reported for cold-crystallized samples in the $100-190{ }^{\circ} \mathrm{C}$ range. The Interface Distribution Function analysis is also employed to provide the crystalline and amorphous layer thickness values at various temperatures of interest. Results suggest that samples crystallized at both low $\left(T_{\mathrm{a}}=100-120^{\circ} \mathrm{C}\right)$ and high $\left(T_{\mathrm{a}}=160-190^{\circ} \mathrm{C}\right)$ temperatures are subjected to a nearly continuous nanostructural reorganization process upon heating, starting immediately above $T_{\mathrm{g}}\left(\approx 80^{\circ} \mathrm{C}\right)$ and giving rise to complete melting at $\approx 260{ }^{\circ} \mathrm{C}$. For all the $T_{\mathrm{a}}$ investigated, a meltingrecrystallization mechanism seems to take place once $T_{\mathrm{a}}$ is exceeded, concurrently to the low-temperature endotherm observed in the DSC scans. For low- $T_{\mathrm{a}}$ and slow heating rates $\left(2{ }^{\circ} \mathrm{C} / \mathrm{min}\right)$, a conspicuous recrystallization process is predominant within $T_{\mathrm{a}}+30^{\circ} \mathrm{C} \leq T \leq 200{ }^{\circ} \mathrm{C}$. In contrast, for high- $T_{\mathrm{a}}$, an increasingly strong melting process is observed. For both, high- and low- $T_{\mathrm{a}}$, an extensive structural reorganization takes place above $200{ }^{\circ} \mathrm{C}$, involving the appearance of new lamellar stacks simultaneously to the final melting process. The two mechanisms should contribute to the high-temperature endotherm in the DSC scan. Finally, the use of a high heating rate is found to hinder the material's overall recrystallization process during the heating run and suggests that the high-temperature endotherm is ascribed to the melting of lamellae generated or thickened during the heating run.
\end{abstract}

(C) 2008 Elsevier Ltd. All rights reserved.

Keywords: PET; X-ray diffraction; Multiple melting

\section{Introduction}

Semicrystalline poly(ethylene terephthalate) (PET) exhibits a multiple melting behaviour upon heating [1-9]. The nature of the various endotherms observed during a differential scanning calorimetry (DSC) scan has been the subject of intense research over the last decades [1-3,5-9]. Similar melting behaviour has also been observed for poly(ethylene naphthalene-2,6-dicarboxylate) (PEN) and poly(ether ether ketone)

\footnotetext{
* Corresponding author. Tel.: +34 91 5619408; fax: +34 915642431.

E-mail address: embalta@iem.cfmac.csic.es (F.J. Baltá Calleja).
}

(PEEK) [10-14]. The interpretation of the various endothermic processes taking place in PET upon heating most frequently conforms to one of the two following viewpoints: (a) a melting-recrystallization-remelting process [1]; (b) the melting of secondary and primary lamellae [2]. At the heart of this controversy underlies the debate on the detailed nanostructure of PET, whether constituted by stacks of lamellae separated by pockets of amorphous material [15] or by homogeneously distributed lamellar stacks [16].

In the above first mentioned nanostructural model for semicrystalline PET, in which lamellar stacks are separated by domains of amorphous material, the low-temperature melting endotherm observed in the DSC scans is often attributed to 
the melting of thinner (secondary) crystals. Melting of primary lamellae stacks gives rise to the high-temperature endotherm, in the case of dual melting behaviour, or to a middle temperature endotherm, in the case of triple melting behaviour. In the latter case, the final endotherm is often associated to recrystallization or crystal perfection during heating. Modulated DSC studies carried out in melt crystallized PET have offered evidence of an exothermic process taking place almost simultaneously to the melting of secondary crystals [6]. Hence, the multiple endotherm behaviour was attributed to the combination of a recrystallization process inducing a large level of crystal reorganization and the melting of a dual lamellar stack population [6]. Moreover, recent fast $(2700 \mathrm{~K} / \mathrm{s})$ calorimetric studies in melt crystallized PET films show a single broad melting peak associated to the occurrence of a monomodal distribution of lamellae thicknesses [9]. In this case, the authors attributed the multiple melting behaviour of PET to a continuous melting-recrystallization-remelting process taking place upon heating.

The present paper intends to contribute to the understanding of the nanostructural reorganization processes taking place in cold-crystallized PET upon heating. Our aim is to report recent simultaneous wide- and small-angle X-ray scattering (WAXS and SAXS, respectively) measurements on various cold-crystallized PET samples, as a function of temperature, using a synchrotron radiation source. DSC studies are also employed to provide complementary information on the various mechanisms taking place in cold-crystallized PET upon heating. The influence of heating rate is also discussed.

\section{Experimental}

\subsection{Materials}

The starting glassy PET material (Goodfellow, ES301465, $M_{\mathrm{w}}=20,000 \mathrm{~g} / \mathrm{mol}$ ) was supplied in the form of films $\approx 350 \mu \mathrm{m}$ thick. Rectangular-shaped samples were cut from the as-received sheets and crystallized from the glass for $9 \mathrm{~h}$ under vacuum at different annealing temperatures in the range $100-190{ }^{\circ} \mathrm{C}$.

\subsection{Techniques}

Differential scanning calorimetry measurements were carried out using a Perkin-Elmer DSC-7 in the range from $40{ }^{\circ} \mathrm{C}$ to $300{ }^{\circ} \mathrm{C}$ and at a heating rate of $2{ }^{\circ} \mathrm{C} / \mathrm{min}$ and $40{ }^{\circ} \mathrm{C} /$ min under nitrogen flux. Calibration of the temperature was made using indium.

Simultaneous WAXS and SAXS patterns were obtained using a synchrotron radiation source at DESY, HASYLAB (beamline A2). A wavelength of $\lambda=1.50 \AA$ was employed.

WAXS patterns were recorded in the range $10^{\circ} \leq 2 \theta \leq 28.5^{\circ}$, using a one-dimensional detector. The sample-detector distance was $30 \mathrm{~cm}$. The data were corrected for the detector response and beam intensity, and calibrated against a highly crystalline PET reference sample. The amorphous halo of PET was fitted to the diffraction curve of each sample for the estimation of the degree of crystallinity, $\alpha_{\text {WAXS }}$, which was calculated from the ratio of the area under the crystalline peaks to that of the total diffraction curve. Furthermore, the crystalline peaks were fitted to Lorentzian curves and the crystal size derived from the coherence length along the $(h k l)$ direction, $D_{h k l}$, was estimated from the integral breadth of each reflection, $\sigma_{h k l}$, following [17]:

$D_{h k l}=\frac{\lambda}{\sigma_{h k l} \cos \theta}$

The crystal coherence values reported in this paper should be taken as a minimum value, due to the fact that one should expect peak broadening due to lattice distortions and instrumental effects [17]. However, we assume that this approximation does not substantially affect the relative variations in $D_{h k l}$ upon heating [18].

SAXS patterns were collected using a mar CCD camera placed at $294 \mathrm{~cm}$ from the sample. The centre of the primary beam was displaced to the bottom of the detector, in order to record the scattered intensity, $I(s)$, over a wide range of scattering vector values, $s\left(s=2 \sin \theta / \lambda, 0.02 \leq s \leq 0.3 \mathrm{~nm}^{-1}\right)$. The intensity distribution scans as a function of $s$ were obtained from the azimuthal integration of the two-dimensional SAXS patterns over the angular range 89.5-90.5 . Calibration against a rat tendon tail standard was accomplished. The intensity values were corrected for the beam intensity and the background scattering was subtracted. The intensity profiles were fitted to a non-symmetrical function, after application of the Lorentz correction. The long period values, $L$, were derived from the $s$ value at maximum intensity, following Bragg's law.

The average values of the crystalline, $l_{\mathrm{c}}$, and amorphous, $l_{\mathrm{a}}$, layer thicknesses of the cold-crystallized samples at room temperature were obtained from the Interface Distribution Function (IDF), $g_{1}(r)$ [19]. The $l_{\mathrm{c}}$ and $l_{\mathrm{a}}$ values were determined within less than $8 \%$ standard deviation error, after averaging the data for two different samples. For $T_{\mathrm{a}}=120^{\circ} \mathrm{C}$, $g_{1}(r)$ was also evaluated as a function of temperature. The $g_{1}(r)$ function is derived from the one-dimensional Fourier transformation of the interference function $G_{1}(s)$ of the two-phase system, following [19]:

$g_{1}(r)=2 \int_{0}^{\infty} G_{1}(s) \cos (2 \pi s r) \mathrm{d} s$

The $g_{1}(r)$ function is proportional to the second derivative of the correlation function and represents the probability of finding interfaces between a crystal and the adjacent amorphous region at a distance $r$. To obtain a smooth $G_{1}(s)$ function, a Butterworth low-pass filter was employed [19,20]. After application of Porod's law, a Hanning filtering was also used [20,21]. For the room temperature (RT) measurements, a model of coupled finite paracrystalline stacks was used to obtain the $l_{\mathrm{c}}$ and $l_{\mathrm{a}}$ values from $g_{1}(r)$ [19]. This model univocally determines the $l_{\mathrm{c}}$ and $l_{\mathrm{a}}$ values. On the other hand, for $T_{\mathrm{a}}=120^{\circ} \mathrm{C}$, the $g_{1}(r)$ function was computed at various temperatures of 
interest. In this case, $g_{1}(r)$ was better fitted to a model of infinite paracrystalline stacks [19]. The lamellar thickness value with the smallest relative variance was attributed to the crystalline lamellar thickness.

\section{Results}

\subsection{Multiple melting behaviour as revealed by DSC}

Fig. 1 illustrates the DSC scans of the cold-crystallized samples at different $T_{\mathrm{a}}$, for $2{ }^{\circ} \mathrm{C} / \mathrm{min}$. The inset of Fig. 1 includes the DSC scans carried out at $40{ }^{\circ} \mathrm{C} / \mathrm{min}$. A multiple melting behaviour is observed in both cases. Similar experiments carried out at $10{ }^{\circ} \mathrm{C} / \mathrm{min}$ (not shown here) also present this behaviour for $100{ }^{\circ} \mathrm{C} \leq T_{\mathrm{a}} \leq 190{ }^{\circ} \mathrm{C}$. The main features of the low (I) and the high (II) temperature endotherms observed in the DSC scans of cold-crystallized PET using heating rates in the range $2-40{ }^{\circ} \mathrm{C} / \mathrm{min}$ are the following:

1. Endotherm I appears at temperatures slightly above the isothermal crystallization temperature, as it is well documented [2-7]. The onset of endotherm I is approximately the same for the slow and the rapid heating rates, however, the maximum appears at $\approx T_{\mathrm{a}}+10{ }^{\circ} \mathrm{C}$ in the case of $2{ }^{\circ} \mathrm{C} /$ min and at $T_{\mathrm{a}}+20^{\circ} \mathrm{C}$ for a heating rate of $40{ }^{\circ} \mathrm{C} / \mathrm{min}$. Results also show that the melting point of this endotherm is linearly related with $T_{\mathrm{a}}$, in agreement with previous published data [7].

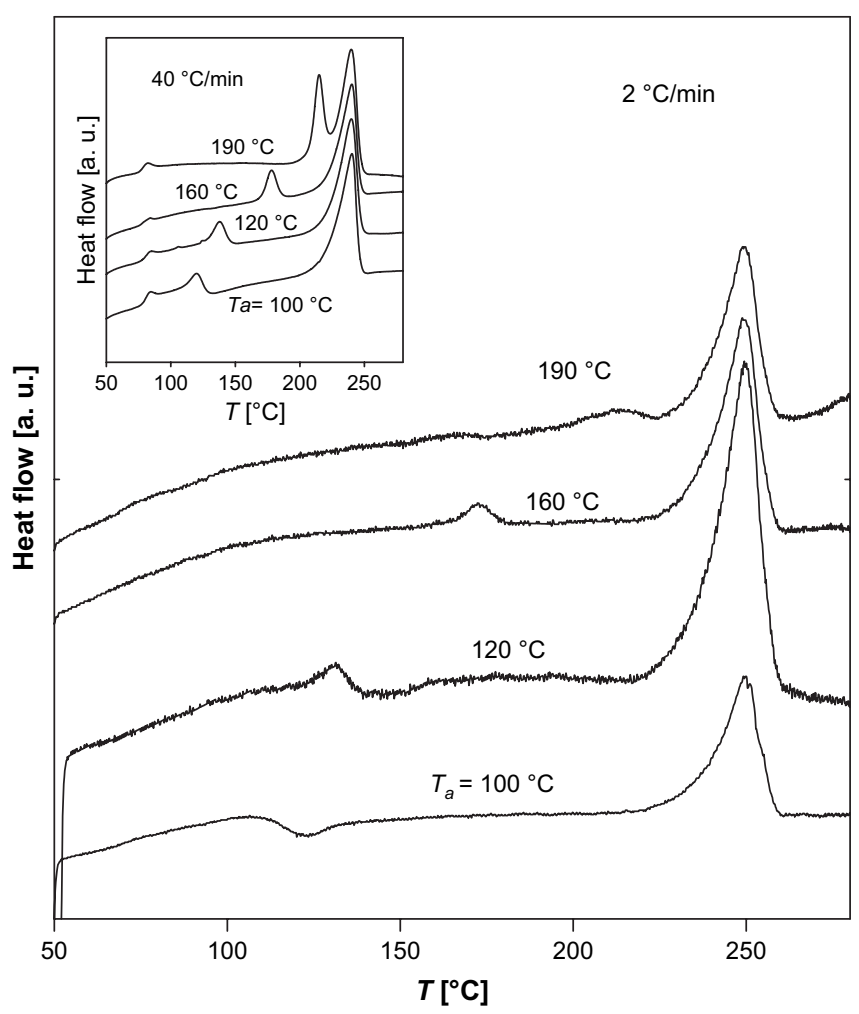

Fig. 1. DSC scans at $2{ }^{\circ} \mathrm{C} / \mathrm{min}$ of the PET samples cold-crystallized at different temperatures, $T_{\mathrm{a}}$. The inset shows measurements carried out at $40^{\circ} \mathrm{C} / \mathrm{min}$.
2. Endotherm II appears always at the same temperature, independently of $T_{\mathrm{a}}$, as one would expect from previous published work [2,5-7]. However, increasing the heating rate shifts the melting position to slightly lower values.

\subsection{Nanostructural changes upon heating as revealed by WAXS and SAXS}

Figs. 2 and 3 illustrate the plot of the degree of crystallinity, $\alpha_{\text {WAXS }}$, and the lateral crystal size along the (100) direction, $D_{100}$, respectively, derived from WAXS, in the course of a heating cycle at $2{ }^{\circ} \mathrm{C} / \mathrm{min}$, for the PET samples annealed at various temperatures.

Fig. 2 shows that for the high-temperature annealed samples $\left(T_{\mathrm{a}}=160{ }^{\circ} \mathrm{C}\right.$ and $\left.190{ }^{\circ} \mathrm{C}\right)$, a continuous $\alpha_{\text {WAXs }}$-decrease with increasing $T$ is observed, starting at around $80{ }^{\circ} \mathrm{C}\left(T_{\mathrm{g}} \approx 80^{\circ} \mathrm{C}\right.$, see inset of Fig. 1) up to $260{ }^{\circ} \mathrm{C}$, where the crystallinity tends to vanish. In this temperature interval, the $\alpha_{\text {WAXs }}$ rate of decrease, $\mathrm{d} \alpha_{\text {WAXS }} / \mathrm{d} T$, progressively increases as the temperature is raised. Results suggest that an increasingly strong melting process predominates over the entire temperature range, starting on the vicinity of the glass transition temperature. On the other hand, for the low-temperature annealed materials $\left(T_{\mathrm{a}}=100{ }^{\circ} \mathrm{C}\right.$ and $\left.120^{\circ} \mathrm{C}\right), \alpha_{\text {WAXs }}$ exhibits the same initial decrease with increasing $T$ observed in the high- $T_{\mathrm{a}}$ ones immediately after $T_{\mathrm{g}}$. However, in the former case (low $-T_{\mathrm{a}}$ ), the $\alpha_{\mathrm{WAXS}}$ values tend to stabilize at temperatures around $T_{\mathrm{a}}$, and remain constant for $20-30{ }^{\circ} \mathrm{C}$. Thereafter, $\alpha_{\text {WAXs }}$ increases, and $\mathrm{d} \alpha_{\text {WAXS }} / \mathrm{d} T$

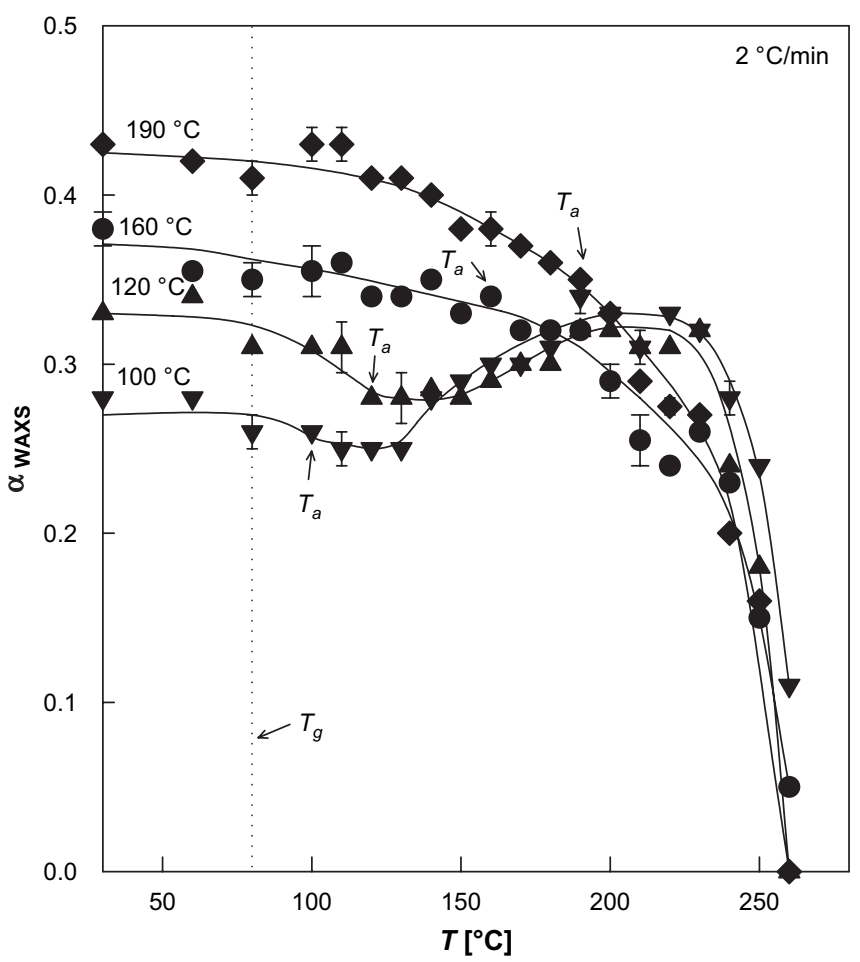

Fig. 2. Degree of crystallinity, as determined by WAXS, as a function of temperature for the PET samples crystallized from the glassy state at $100{ }^{\circ} \mathrm{C}(\boldsymbol{\nabla})$, $120{ }^{\circ} \mathrm{C}(\boldsymbol{\Delta}), 160{ }^{\circ} \mathrm{C}(\boldsymbol{\bullet})$ and $190^{\circ} \mathrm{C}(\diamond)$. The heating rate was $2{ }^{\circ} \mathrm{C} / \mathrm{min}$. 


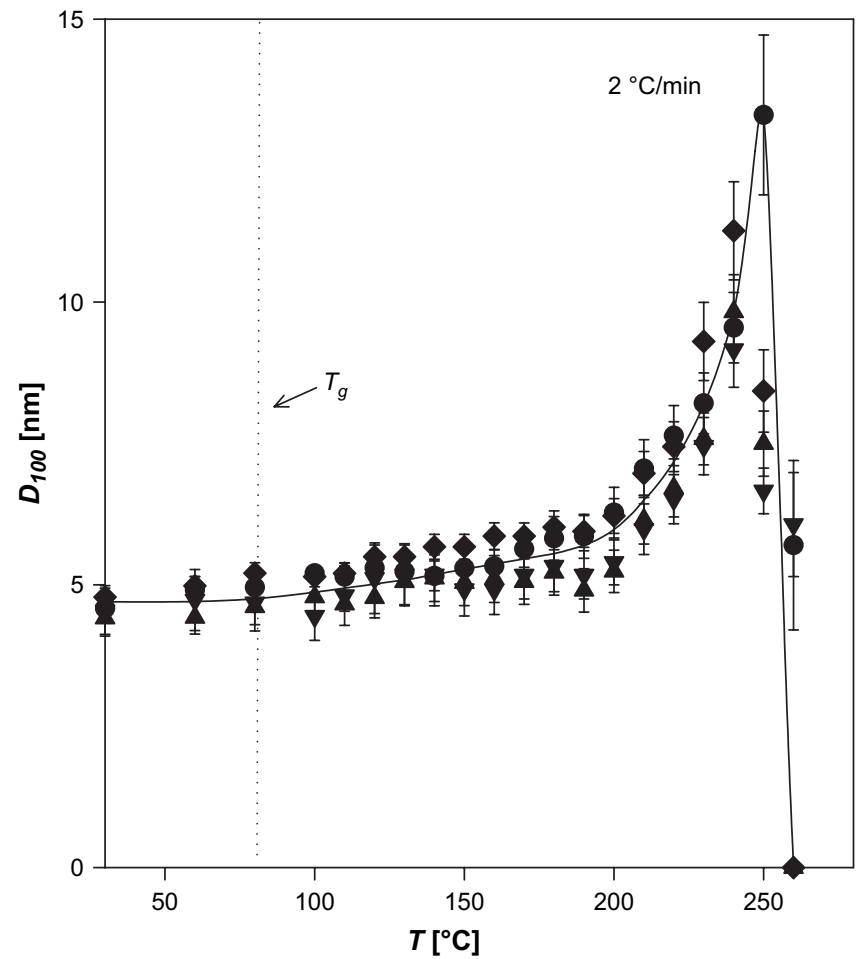

Fig. 3. Variation in the lateral crystal size along the (100) direction during a heating run at $2{ }^{\circ} \mathrm{C} / \mathrm{min}$, for the PET samples crystallized from the glassy state at various $T_{\mathrm{a}}$. $D_{100}$ values were calculated according to Eq. (1). Symbols as in Fig. 2. The solid line is a guide to the eye.

decreases, with increasing $T$, in such a way that the $\alpha_{\text {WAXS }}$ values level-off at about $200{ }^{\circ} \mathrm{C}$. Finally, $\alpha_{\text {WAXs }}$ conspicuously diminishes a few degrees above $200{ }^{\circ} \mathrm{C}$, approaching $\approx 0$ at $260^{\circ} \mathrm{C}$. From these results, one may already infer that, for PET crystallized from the glassy state at low $-T_{\mathrm{a}}$, a combination of melting and recrystallization processes take place upon heating, starting on the vicinity of $T_{\mathrm{g}}$.

The overall $D_{100}$ behaviour with $T$ seems to be very similar for both, the low- and the high- $T_{\mathrm{a}}$ materials (see Fig. 3). In both cases, a moderate crystal size increase with increasing $T$ is first observed from $\approx 80{ }^{\circ} \mathrm{C}$ up to $\approx 200{ }^{\circ} \mathrm{C}$; at higher temperatures, a conspicuous rise is detected. It is noteworthy that the $D_{100}$ values do not seem to substantially vary during the $\alpha_{\text {WAXs }}{ }^{-}$ rise observed for the low- $T_{\mathrm{a}}$ materials, from $T_{\mathrm{a}}+20{ }^{\circ} \mathrm{C}$ up to $\approx 200{ }^{\circ} \mathrm{C}$. Furthermore, the sudden $D_{100}$-drop observed at $250-260{ }^{\circ} \mathrm{C}$ can be related to the fact that the sample is approaching complete melting and the still remaining crystallites are significantly distorted.

Fig. 4 shows the plot of the long period values as a function of temperature, for the various cold-crystallized PET samples $\left(2^{\circ} \mathrm{C} /\right.$ min). In all cases, $L$ remains approximately constant up to $80^{\circ} \mathrm{C}$, where the $L$ values start to rise as a function of $T$. The rate of $L$ increase, $\mathrm{d} L / \mathrm{d} T$, upon heating remarkably depends on the temperature at which the sample was crystallized. Hence, for $T_{\mathrm{a}}=190{ }^{\circ} \mathrm{C}, \mathrm{d} L / \mathrm{d} T$ is nearly constant from $100^{\circ} \mathrm{C}$ up to $200^{\circ} \mathrm{C}$. In contrast, for the sample annealed at $100^{\circ} \mathrm{C}, \mathrm{d} L / \mathrm{d} T$ continuously raises from $100{ }^{\circ} \mathrm{C}$ to $200{ }^{\circ} \mathrm{C}$. Finally, the $L$ values for the different annealed materials converge above $200{ }^{\circ} \mathrm{C}$, where a conspicuous

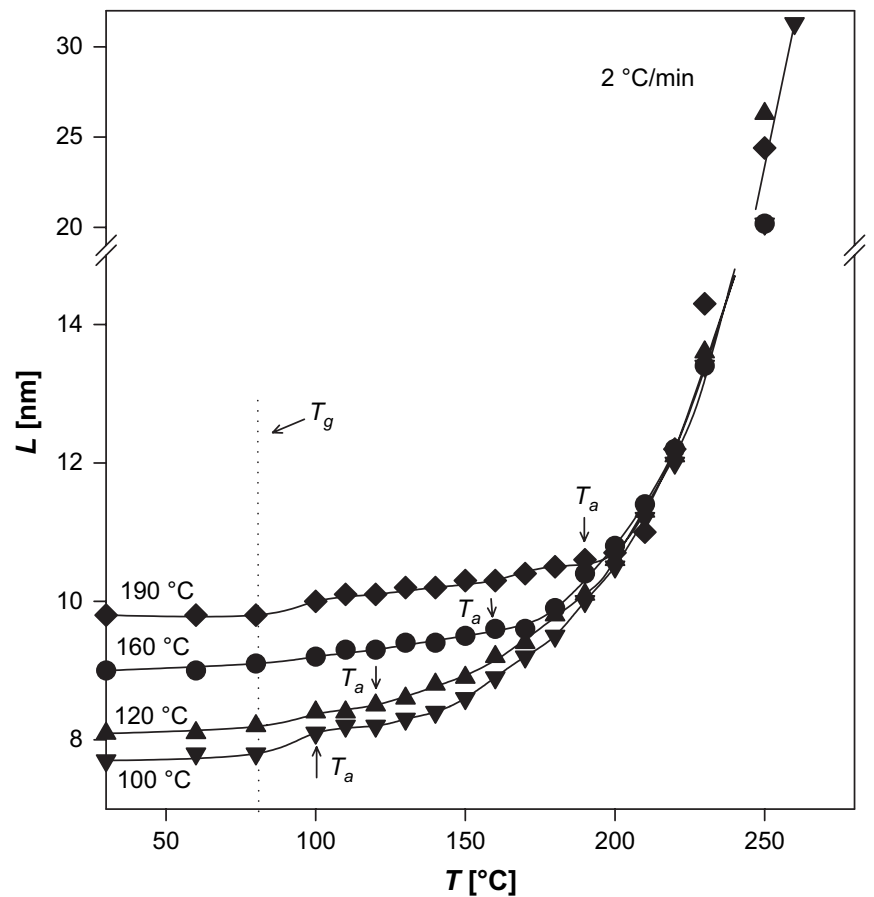

Fig. 4. Long period values as a function of temperature, for the various cold-crystallized samples. Symbols as in Fig. 2. The heating rate employed was $2{ }^{\circ} \mathrm{C} / \mathrm{min}$.

rise with increasing temperature is observed for all annealed samples up to $260{ }^{\circ} \mathrm{C}$. The $L$ values at $260^{\circ} \mathrm{C}$ for the samples annealed at $120^{\circ} \mathrm{C}-190{ }^{\circ} \mathrm{C}$ are not included in Fig. 3 due to the fact that these data are beyond the resolution of our SAXS set-up, and only a small portion of the scattering curve could be detected.

\subsection{Influence of heating rate}

Figs. 5-7 illustrate the $\alpha_{\text {WAXs }}, D_{100}$ and $L$ values, respectively, as a function of $T$, obtained for the various cold-crystallized PET materials at much higher heating rate: $40{ }^{\circ} \mathrm{C} / \mathrm{min}$. Due to the limited number of data, the $\alpha_{\text {WAXS }}, L$ and $D_{100}$ behaviours upon heating is not as clearly defined as it is for $2{ }^{\circ} \mathrm{C} / \mathrm{min}$. However, one can see that in the case of $40^{\circ} \mathrm{C} /$ min, the overall $\alpha_{\text {WAXs }}$ and $L$ behaviours upon heating are somehow shifted towards higher temperatures with respect to that observed at $2{ }^{\circ} \mathrm{C} / \mathrm{min}$. Indeed, for $T_{\mathrm{a}}=100{ }^{\circ} \mathrm{C}$ (see Fig. 5), the initial $\alpha_{\text {WAXs }}$-decrease with increasing $T$ and subsequent level-off is followed by a $\alpha_{\text {WAXs-rise at }} \approx 180{ }^{\circ} \mathrm{C}$. In the case of $2{ }^{\circ} \mathrm{C} / \mathrm{min}$ (see Fig. 2), the $\alpha_{\text {WAXs }}$ values for $T_{\mathrm{a}}=100{ }^{\circ} \mathrm{C}$ already increase at $140{ }^{\circ} \mathrm{C}$. As a consequence of this temperature shift, the degree of crystallinity during the rapid heating cycle, only slightly improves in a limited temperature interval $\left(175-225^{\circ} \mathrm{C}\right)$ prior to the final melting (see Fig. 5). Furthermore, for $T_{\mathrm{a}}=120^{\circ} \mathrm{C}$, no crystallinity increase is observed before the final melting process is detected. In addition, Fig. 7 shows that there is also a shift of $\approx 20{ }^{\circ} \mathrm{C}$ in the temperature at which $L$ conspicuously rises with increasing temperature $\left(\approx 220^{\circ} \mathrm{C}\right)$, with respect to that observed when applying a slow heating rate $\left(\approx 200{ }^{\circ} \mathrm{C}\right.$, see Fig. 4). Finally, the lateral crystal size behaviour substantially changes with 


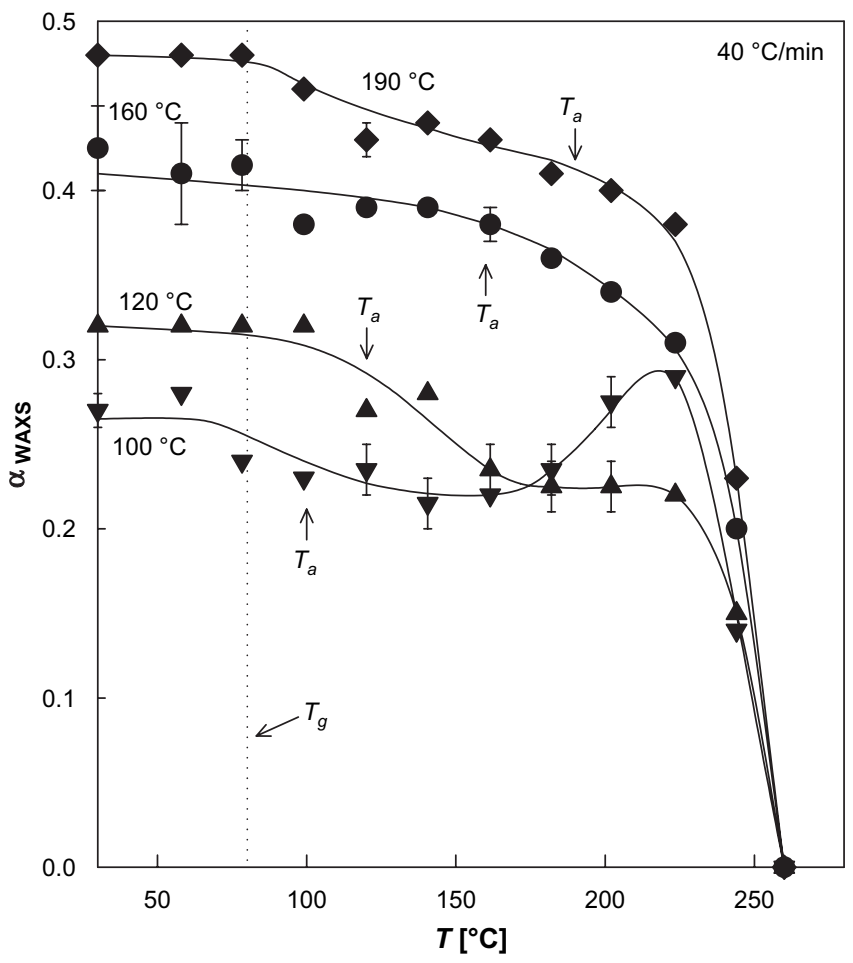

Fig. 5. Variation in the degree of crystallinity during a heating cycle at $40{ }^{\circ} \mathrm{C} /$ min, for the PET samples crystallized from the glassy state at various $T_{\mathrm{a}}$. Symbols as in Fig. 2.

the different heating rates employed (see Figs. 3 and 6); in the case of $40{ }^{\circ} \mathrm{C} / \mathrm{min}$, a much lower $D_{100}$-increase is observed upon heating, especially at high temperatures, prior to the final $D_{100}$-drop.

\section{Discussion}

Table 1 summarizes the values at room temperature of $l_{\mathrm{c}}, l_{\mathrm{a}}$, and the linear degree of crystallinity $\alpha_{\mathrm{L}}=\left(l_{\mathrm{c}} / l_{\mathrm{c}}+l_{\mathrm{a}}\right)$, obtained from the IDF analysis of the samples cold-crystallized at $100{ }^{\circ} \mathrm{C}, 120^{\circ} \mathrm{C}$ and $160{ }^{\circ} \mathrm{C}$. The $\alpha_{\text {WAXs }}$ data are also included for completeness. It is noteworthy that the linear degree of crystallinity is approximately the same for all the materials, while $\alpha_{\text {WAXs }}$ increases as $T_{\mathrm{a}}$ is raised. This result suggests that the amount of amorphous material outside the lamellar stacks $\left(1-\alpha_{\text {WAXS }} / \alpha_{\mathrm{L}}\right)$ significantly decreases as $T_{\mathrm{a}}$ increases. Upon heating, low- and high- $T_{\mathrm{a}}$ materials exhibit a different behaviour, as revealed by the WAXS and SAXS results shown in Figs. 2-7. A detailed discussion is offered below.

\subsection{Nanostructural changes on low- $T_{a}$ samples upon heating}

Fig. 8 illustrates, as an example, the comparison between the DSC, SAXS and WAXS results obtained for the PET sample cold-crystallized at $120{ }^{\circ} \mathrm{C}$, using a slow heating rate $\left(2{ }^{\circ} \mathrm{C} / \mathrm{min}\right)$. The $l_{\mathrm{c}}, l_{\mathrm{a}}$ and $\alpha_{\mathrm{L}}$ values, obtained from the IDF analysis of the scattering curves at given temperatures are also included. The use of a rapid heating rate $\left(40^{\circ} \mathrm{C} / \mathrm{min}\right)$ will be discussed in Section 4.3.

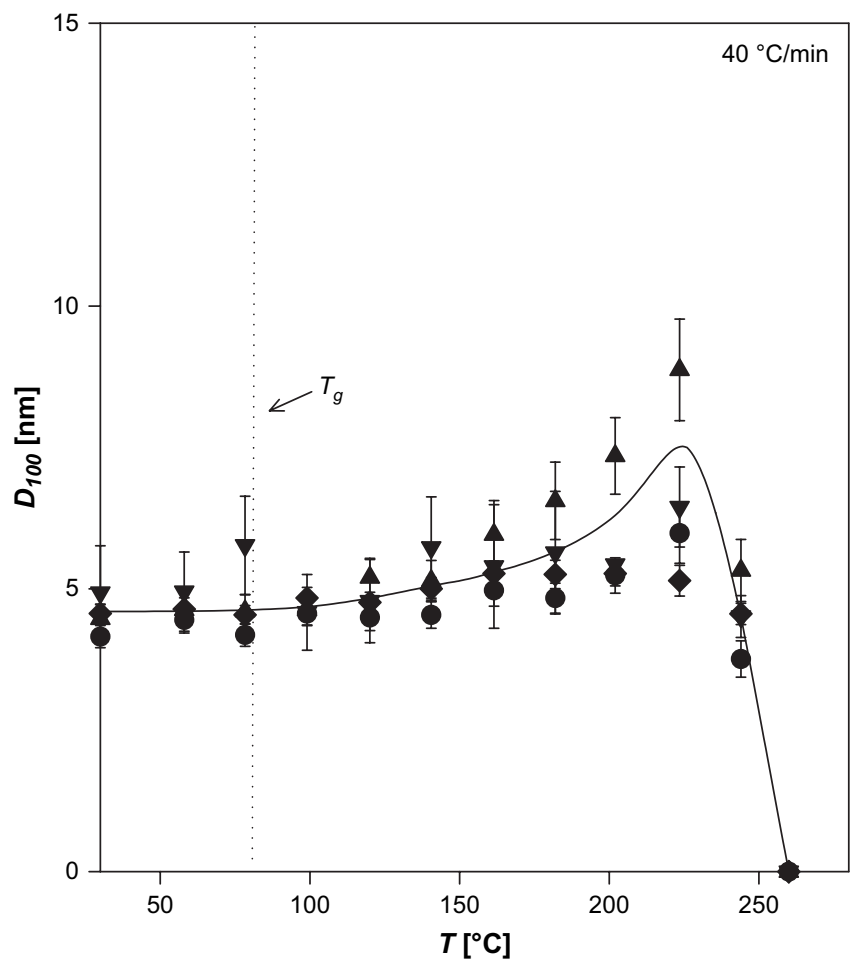

Fig. 6. Plot of the lateral crystal size values along the (100) direction as a function of temperature for all the PET cold-crystallized samples investigated (heating rate $=40{ }^{\circ} \mathrm{C} / \mathrm{min}$ ). Symbols as in Fig. 2. The solid line is a guide to the eye.

Fig. 9 schematically illustrates the representative lamellar arrangement at the end of various temperature ranges during a heating cycle at $2{ }^{\circ} \mathrm{C} / \mathrm{min}$, for one of the low- $T_{\text {a }}$ samples $\left(T_{\mathrm{a}}=120^{\circ} \mathrm{C}\right)$. The scheme has been drawn according to the

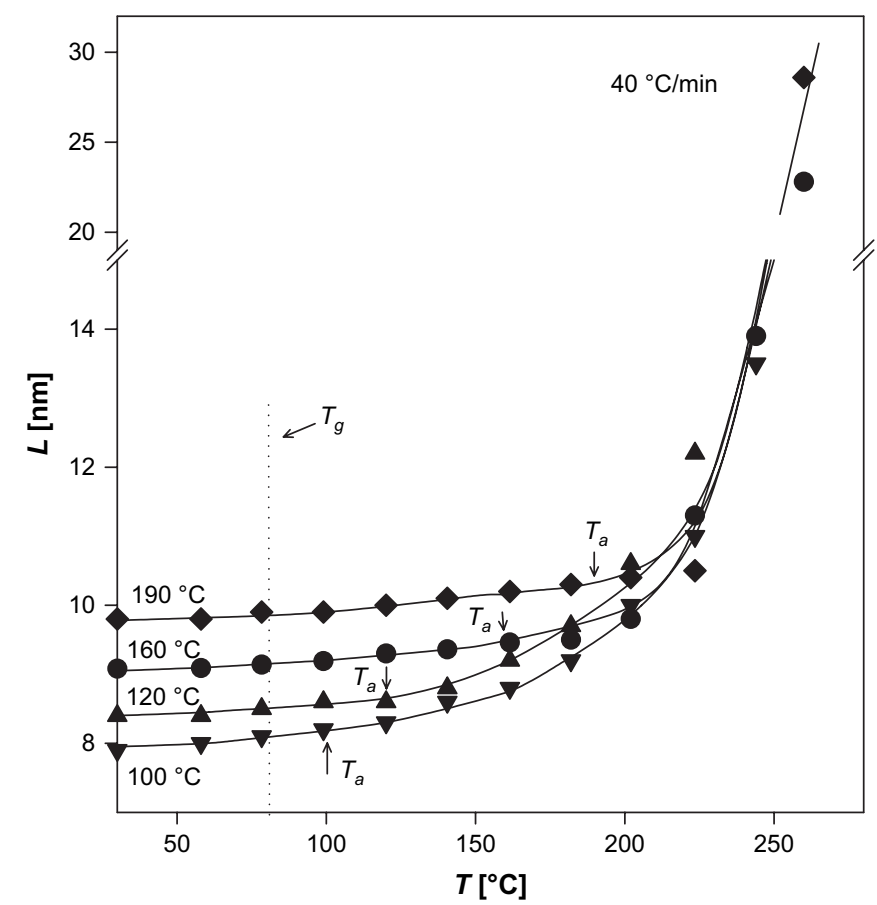

Fig. 7. Long spacing values versus temperature, for all the cold-crystallized PET samples. The heating rate employed was $40{ }^{\circ} \mathrm{C} / \mathrm{min}$. Symbols as in Fig. 2. 
Table 1

Crystal thickness, $l_{\mathrm{c}}$, amorphous thickness, $l_{\mathrm{a}}$, and linear degree of crystallinity, $\alpha_{\mathrm{L}}$, obtained from the IDF analysis of the SAXS diffraction curves for the different $T_{\mathrm{a}}$ samples

\begin{tabular}{lllll}
\hline$T_{\mathrm{a}}\left[{ }^{\circ} \mathrm{C}\right]$ & $l_{\mathrm{c}}[\mathrm{nm}]$ & $l_{\mathrm{a}}[\mathrm{nm}]$ & $\alpha_{\mathrm{L}}$ & $\alpha_{\text {WAXS }}$ \\
\hline 100 & 2.8 & 3.6 & 0.44 & 0.28 \\
120 & 2.5 & 4.2 & 0.38 & 0.33 \\
160 & 3.4 & 4.3 & 0.44 & 0.38 \\
\hline
\end{tabular}

Data for the volume degree of crystallinity, $\alpha_{\text {WAXS }}$, as determined from WAXS, are also included.

WAXS and SAXS data shown in Fig. 8. For the sake of clarity, the following simplifications have been adopted in Fig. 9: (i) the size of the domains that coherently diffract along the (100) direction, $D_{100}$, is not illustrated. The lateral crystal size depicted in Fig. 9 should approach that of the crystalline morphological units commonly detected by electron microscopy techniques; (ii) only the average lamellar thickness has been drawn and not the distribution of lamellar thicknesses; (iii) the lamellar stacks are arranged parallel to each other along the direction perpendicular to the lamellar surfaces. However, this arrangement is only schematic and does not imply that there is a super-lattice array.

For low- $T_{a}$ samples, the following temperature intervals seem to determine the main nanostructural variations upon heating at $2{ }^{\circ} \mathrm{C} / \mathrm{min}$ (see Figs. $2-4$ and 8 ):

- $80{ }^{\circ} \mathrm{C} \leq T \leq T_{a}$, range $\mathrm{I}$ : in this temperature interval, the degree of crystallinity slightly decreases, while $D_{100}, L$,

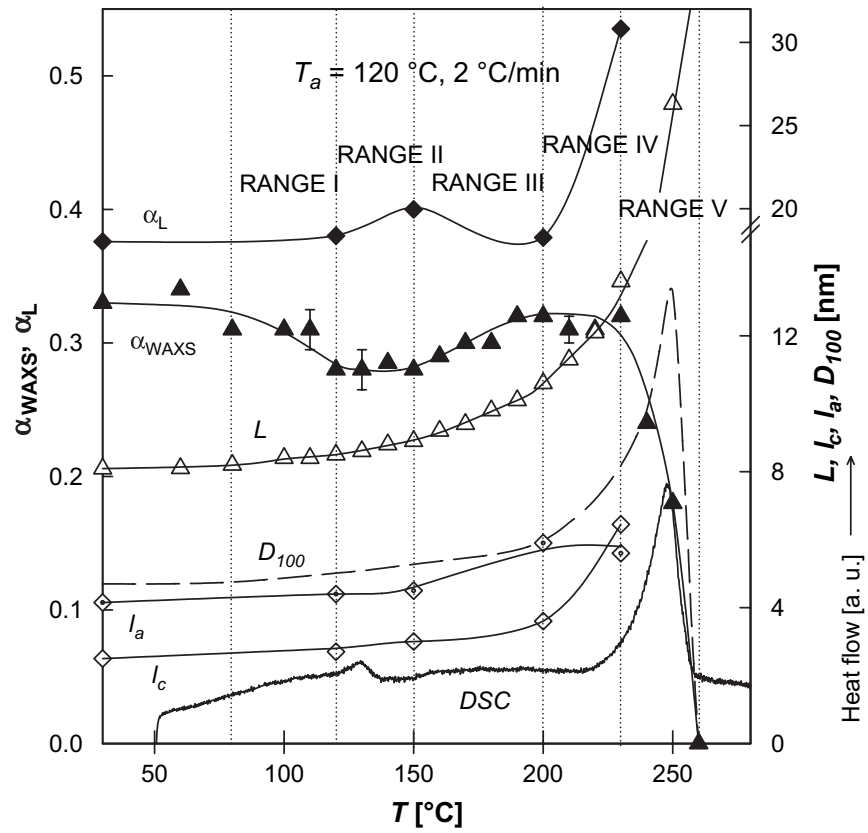

Fig. 8. Comparison of the $\alpha_{\text {WAXS }}(\boldsymbol{\Delta}), L(\triangle), D_{100}$ (dashed line), and calorimetric data (solid line at the bottom of the Figure), as a function of temperature, for the PET sample crystallized at $120^{\circ} \mathrm{C}$ from the glassy state. The crystal and amorphous lamellar thicknesses, $l_{\mathrm{c}}(\diamond)$ and $l_{\mathrm{a}}(\diamond)$, together with the linear degree of crystallinity within the lamellar stacks, $\alpha_{\mathrm{L}}(\diamond)$, as determined from the IDF analysis, are also included at several points during the heating cycle. The heating rate employed was of $2{ }^{\circ} \mathrm{C} / \mathrm{min}$. $l_{\mathrm{c}}$ and $l_{\mathrm{a}}$ slightly increase $\left(\alpha_{\mathrm{L}}\right.$ remains constant), with increasing $T$. The result is consistent with the melting of thinner and more imperfect lamellae, most probably generated during the cooling process from $T_{\mathrm{a}}$ to room temperature, RT. Fig. 9 schematically illustrates this process, starting from the room temperature arrangement of lamellar stacks and leading to a new lamellar organization at the end of range I. For the RT lamellar arrangement, a few crystallites of smaller average crystal thickness, representing those developed during cooling from $T_{\mathrm{a}}$ to RT, can be visualized. From our structural data at RT, one cannot distinguish whether these imperfect and unstable crystallites are inserted within the existing lamellae or appear as separate lamellar stacks in the amorphous pockets. However, the fact that upon heating above $T_{\mathrm{g}}, \alpha_{\mathrm{L}}$ remains approximately constant while $\alpha_{\text {WAXs }}$ significantly decreases (see Fig. 8), suggests that the amount of amorphous material outside the lamellar stacks increases from $T=T_{\mathrm{g}}$ to $T=T_{\mathrm{a}}$ (see Fig. 9, range I). Consequently, we favour the occurrence of thinner lamellae as separate stacks rather than via insertion into the existing ones.

- $T_{a} \leq T \leq T_{a}+30{ }^{\circ} \mathrm{C}$, range $I I:$ here, $\alpha_{\mathrm{WAXS}} \approx$ constant; $D_{100}, L, l_{\mathrm{c}}, l_{\mathrm{a}}$ and $\alpha_{\mathrm{L}}$ slightly increase with increasing $T$. The DSC scan reveals an endothermic process starting at $T_{\mathrm{a}}$, immediately followed (or overlapped) by an apparently small exothermic process that seems to finish at $\approx T_{\mathrm{a}}+30{ }^{\circ} \mathrm{C}$. Results suggest that in this temperature interval, an additional melting and a subsequent recrystallization process initiate, giving rise to new lamellar stacks with a larger degree of crystallinity. Fig. 9 illustrates the new average lamellar stack arrangement at the end of range II. It is noteworthy that the fraction of inter-stack amorphous regions increases.

- $T_{a}+30{ }^{\circ} \mathrm{C} \leq T \leq 200^{\circ} \mathrm{C}$, range III: at $T=T_{\mathrm{a}}+30{ }^{\circ} \mathrm{C}$, the DSC scan levels-off and there is no apparent endothermic or exothermic process in the course of range III. In contrast, it is clearly seen that $\alpha_{\text {WAXs }}$ starts to rise at $T=T_{\mathrm{a}}+30{ }^{\circ} \mathrm{C}$ and only levels-off at approximately $T=200{ }^{\circ} \mathrm{C}$. The result that a significant $\alpha_{\text {WAXs }}$-rise is only observed at $T \geq T_{\mathrm{a}}+30{ }^{\circ} \mathrm{C}$ could be related to the fact that the distribution of relaxation modes associated to the $\alpha$-relaxation is shifted towards higher temperatures after cold crystallization. This was evidenced in our preceding DMTA studies carried out in the starting glassy PET material and the cold-crystallized one at low- $T_{\mathrm{a}}$ [22]. For low- $T_{\mathrm{a}}$ materials, the annealing temperature $T_{\mathrm{a}}$ lies within the temperature interval at which the $\alpha$-process takes place. This result was thoroughly discussed in a preceding paper [22], in terms of a vitrification mechanism taking place within the amorphous regions between crystallites as crystallization proceeds at $T_{\mathrm{a}}$. Hence, significant structural rearrangements can only take place once $T_{\mathrm{a}}$ is overcome by $\approx 30{ }^{\circ} \mathrm{C}$, i.e., close to the end of the $\alpha$-relaxation process. The SAXS and WAXS results reported in the present paper for the low- $T_{\mathrm{a}}$ material confirm this contention. Indeed, once $T=T_{\mathrm{a}}+30^{\circ} \mathrm{C}$ is approached, 


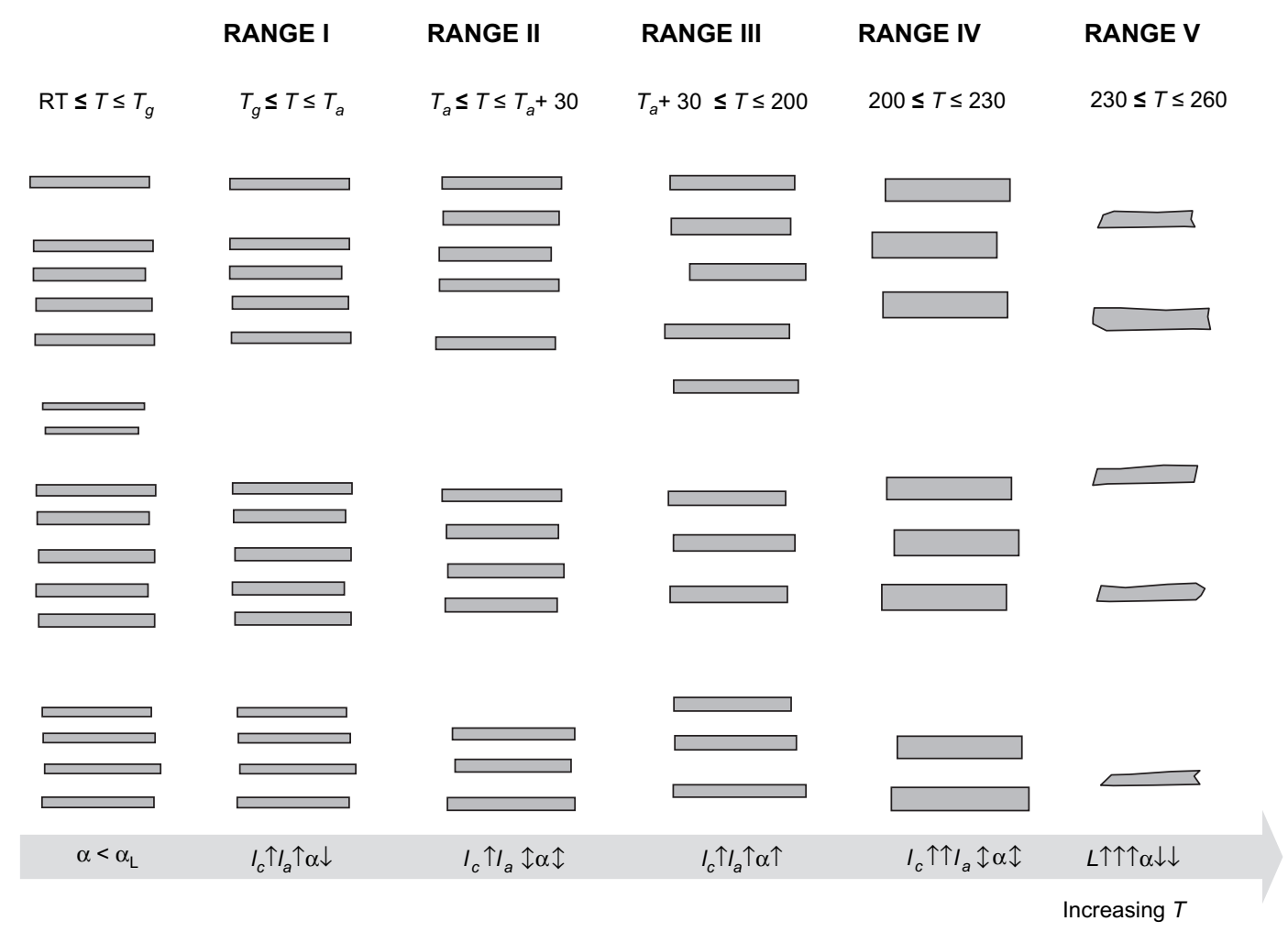

Fig. 9. Schematics of the average lamellar arrangement at the end of each temperature range (in ${ }^{\circ} \mathrm{C}$ ), for $T_{\mathrm{a}}=120{ }^{\circ} \mathrm{C}$. The scheme has been drawn according to the SAXS and WAXS data taken at $2{ }^{\circ} \mathrm{C} / \mathrm{min}$. The arrows at the bottom of the picture represent the extent of the $l_{\mathrm{c}}, l_{\mathrm{a}}$ or $\alpha_{\mathrm{WAXS}}$ variation upon heating, within the corresponding temperature range: increase $(\uparrow)$, decrease $(\downarrow)$; remains constant $(\uparrow)$.

a conspicuous $\alpha_{\text {WAXs }}$ and $L$ rise with increasing $T$ is detected (see Fig. 8, range III). A dominant recrystallization process is observed over the entire temperature interval. Results are consistent with a continuous melting-recrystallization process upon heating, involving the appearance of thicker crystals that consequently melt at higher temperatures. In Fig. 9, the new lamellar arrangement at the end of range III $\left(T=200{ }^{\circ} \mathrm{C}\right)$ is depicted. Here, the $l_{\mathrm{c}}$ and $l_{\mathrm{a}}$ values are enhanced with respect to those characteristic of range II. The material is now nearly space-filled with lamellar stacks, only a small fraction remains outside the lamellar stacks $(\approx 13 \%)$.

$-200^{\circ} \mathrm{C} \leq T \leq 230^{\circ} \mathrm{C}$, range $\mathrm{IV}$ : Fig. 8 shows that the $\alpha_{\text {WAXs }}$ values level-off at around $200{ }^{\circ} \mathrm{C}$ and remain constant up to $230^{\circ} \mathrm{C}$. $L, l_{\mathrm{c}}$ and $D_{100}$ values significantly increase in this temperature range. Moreover, the hightemperature DSC endotherm starts at $\approx 220{ }^{\circ} \mathrm{C}$. Results suggest that the prevailing recrystallization mechanism of range III is now overlapped by the initiation of the final melting process, starting with the melting of the thinner crystals. Fig. 9 schematically illustrates the nanostructural rearrangements taking place at these high temperatures. The increase of the average $l_{\mathrm{c}}$ value at $T_{\mathrm{a}}=230{ }^{\circ} \mathrm{C}$ could be due to the combination of: (i) the melting of thinner crystals and (ii) the recrystallization of new lamellae with larger $l_{\mathrm{c}}$ values. The occurrence of these mechanisms of structural reorganization is discussed below in the light of the results obtained during a rapid heating cycle. In addition, the difference between $\alpha_{\text {WAXs }}$ and $\alpha_{\mathrm{L}}$ at $230{ }^{\circ} \mathrm{C}$ is remarkable. This result evidences the space-filling morphology of the lamellar stacks that are melting at these temperatures (concurrent to the beginning of the endothermic process in the DSC scan), in contrast to the more compacted nanostructure of those emerging.

- $230{ }^{\circ} \mathrm{C} \leq \mathrm{T} \leq 260^{\circ} \mathrm{C}$, range $\mathrm{V}$ : this temperature range can be associated to the main part of the high-temperature endothermal DSC peak. Concurrent to this process, the $\alpha_{\text {WAXs }}$ values conspicuously decrease with increasing $T$, approaching $\approx 0$ at $260{ }^{\circ} \mathrm{C}$. In addition, the $L$ values remarkably increase as $T$ is raised. Finally, an initial $D_{100}$-rise followed by a sudden drop at $250{ }^{\circ} \mathrm{C}$ is also observed. Results are consistent with the occurrence of a final melting process, the thinner crystals' melting in the first place. However, in addition, a recrystallization mechanism also takes place below $\approx 250{ }^{\circ} \mathrm{C}$, contributing to the $D_{100}$ and $L$ enhancements observed, as will be discussed in Section 4.3 below. Fig. 9 illustrates the schematics of the lamellar arrangement at temperatures close to complete melting, slightly below $260{ }^{\circ} \mathrm{C}$.

\subsection{High- $T_{a}$ versus low $-T_{a}$ materials}

For high-T $T_{a}$, the following observations can be drawn from the SAXS and WAXS results reported in Figs. 2-4, as compared to the low- $T_{\mathrm{a}}$ samples: 
- The $\alpha_{\text {WAXS }}$ behaviour as a function of temperature is substantially different from that observed for the low- $T_{\mathrm{a}}$ samples (see Fig. 2). Results suggest that, in the case of high- $T_{\mathrm{a}}$, there is a dominant melting process taking place over the entire temperature range. For $T_{\mathrm{g}}<T<T_{\mathrm{a}}$, the

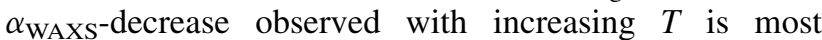
probably related to the melting of lamellae that are generated during the cooling process to RT, immediately after the crystallization from the glassy state at $T_{\mathrm{a}}$. On the other

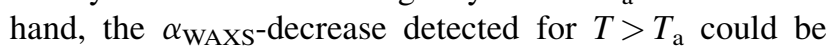
attributed to the melting of the lamellae generated at $T_{\mathrm{a}}$. There is no apparent recrystallization process at $T>T_{\mathrm{a}}$ (see Fig. 2), in contrast to the results shown for low- $T_{\mathrm{a}}$. There are several explanations to account for this behaviour: (i) the high- $T_{\mathrm{a}}$ materials exhibit higher levels of crystallinity than the low-temperature annealed ones, and hence, recrystallization should not be as significant in the formers; (ii) the temperature of cold crystallization for high $-T_{\mathrm{a}}$ lies beyond the end of the main $\alpha$-process; hence, there is no evidence of a vitrification mechanism taking place in the course of crystallization that could subsequently reverse upon heating a few degrees above $T_{\mathrm{a}}$, giving rise to a significant recrystallization mechanism, as discussed for the low- $T_{\mathrm{a}}$ materials; (iii) finally, it should be noted that if any recrystallization process has to take place some degrees above $T_{\mathrm{a}}$, then, it would soon overlap with the initiation of the final melting process.

- Both the high- and the low- $T_{\mathrm{a}}$ samples exhibit the same $D_{100}$ trend with increasing temperature (see Fig. 3). From this result, one concludes that the prominent recrystallization process taking place at $T_{\mathrm{a}}<T<200{ }^{\circ} \mathrm{C}$ during the heating cycle of the low- $T_{\mathrm{a}}$ materials (see Fig. 2) does not significantly enhance the average lateral crystal size. Moreover, the fact that $D_{100}$ exhibits a similar behaviour for the low- and the high- $T_{\mathrm{a}}$ materials for $T>200{ }^{\circ} \mathrm{C}$ suggests that a similar melting-recrystallization process also takes place for high- $T_{\mathrm{a}}$, similarly to that suggested for low $-T_{\mathrm{a}}$.

- Fig. 4 shows that the $L$ increase upon heating from $80^{\circ} \mathrm{C}$ up to $200{ }^{\circ} \mathrm{C}$ is significantly smaller for the high- $T_{\mathrm{a}}$ materials than for the low- $T_{\mathrm{a}}$ ones. It is noteworthy that, both for the low- and the high- $T_{\mathrm{a}}$ materials, $\mathrm{d} L / \mathrm{d} T$ significantly increases as soon as $T_{\mathrm{a}}$ is exceeded, coinciding with the appearance of the low-temperature endotherm of the DSC scans (see Fig. 1). The $L$ increase with increasing $T$ for $80{ }^{\circ} \mathrm{C}<T<T_{\mathrm{a}}$ is related to the melting of thin and imperfect crystals originated during the cooling process from $T_{\mathrm{a}}$ to room temperature. In the case of high- $T_{\mathrm{a}}$, this mechanism is present in a significant fraction of the heating interval investigated. In contrast, for low- $T_{\mathrm{a}}$, the melting of lamellae generated during the cooling process from $T_{\mathrm{a}}$ to room temperature only occurs over a limited temperature interval $\left(T_{\mathrm{a}}-80{ }^{\circ} \mathrm{C}=20-40{ }^{\circ} \mathrm{C}\right)$. In this case, the enhanced $L$-increase observed from $T_{\mathrm{a}}$ up to $\approx 200^{\circ} \mathrm{C}$ is attributed to an extensive structural rearrangement involving the melting and recrystallization of lamellae originated at $T_{\mathrm{a}}$ or during the heating cycle. Finally, for $T>200{ }^{\circ} \mathrm{C}$, the $L$ values for all the materials converge. This agrees with our previous suggestion that a melting-recrystallization process is responsible for the structural reorganization taking place at these temperatures for both the high- and the low $-T_{\mathrm{a}}$ materials.

\subsection{Influence of heating rate}

Comparison of Figs. 2 and 5 reveals that the general $\alpha_{\text {WAXs }}$ trend with $T$ is shifted towards higher temperatures for $40{ }^{\circ} \mathrm{C} /$ min with respect to that found for $2{ }^{\circ} \mathrm{C} / \mathrm{min}$. It is evident that the use of a higher heating rate hinders the nanostructure reorganization upon heating. Indeed, for $T_{\mathrm{a}}=120^{\circ} \mathrm{C}$, no crystallinity increase is observed before complete melting. In addition, for all $T_{\mathrm{a}}$, the conspicuous $\alpha_{\mathrm{WAXS}}$-drop above $225^{\circ} \mathrm{C}$ (see Fig. 5), associated to the final melting process, is more clearly defined over a narrower temperature interval, with respect to the $\alpha_{\text {WAXs }}$ behaviour found in the case of $2{ }^{\circ} \mathrm{C} / \mathrm{min}$. It is noteworthy that for $40{ }^{\circ} \mathrm{C} / \mathrm{min}$, all samples are molten at $260{ }^{\circ} \mathrm{C}$, whereas a significant degree of crystallinity still remains for some of the cold-crystallized samples when heating at $2{ }^{\circ} \mathrm{C} /$ min. This result is consistent with the DSC measurements, where the melting peak of the high-temperature endotherm is shifted towards lower temperatures for the higher heating rate (see Fig. 1). Results suggest that endotherm II is ascribed to the melting of lamellae generated or thickened during the heating run: at high heating rates, the time for structural rearrangement is more limited than at low heating rates.

Let us next discuss the $D_{100}$ and $L$ behaviours upon heating at $40{ }^{\circ} \mathrm{C} / \mathrm{min}$ (Figs. 6 and 7 , respectively). The overall $L$ behaviour upon rapid heating is very similar to that found for $2{ }^{\circ} \mathrm{C} / \mathrm{min}$ (see Figs. 4 and 7 ): $\mathrm{d} L / \mathrm{d} T$ significantly increases once $T_{\mathrm{a}}$ is exceeded. However, the $\mathrm{d} L / \mathrm{d} T$ increase above $T_{\mathrm{a}}$ seems to be smaller in the case of $40{ }^{\circ} \mathrm{C} / \mathrm{min}$. As a consequence, the $L$ values in the case of $40{ }^{\circ} \mathrm{C} / \mathrm{min}$, for a given temperature, are significantly lower than those observed for $2{ }^{\circ} \mathrm{C} / \mathrm{min}$, especially for $T \geq 200{ }^{\circ} \mathrm{C}$. On the other hand, the $D_{100}$ behaviour upon rapid heating is substantially different from that observed during a slow cycle (see Figs. 3 and 6). In the case of $40{ }^{\circ} \mathrm{C} / \mathrm{min}$, only a small $D_{100}$-increase is observed upon heating above $200{ }^{\circ} \mathrm{C}$, in contrast to the conspicuous rise detected for $2{ }^{\circ} \mathrm{C} / \mathrm{min}$. This result suggests that the remarkable enhancement of $D_{100}$ observed above $200{ }^{\circ} \mathrm{C}$ for $2{ }^{\circ} \mathrm{C} / \mathrm{min}$ is a consequence of a recrystallization process occurring upon heating, that is hindered in the case of rapid heating. This nanostructural reorganization would also contribute to the $L$ enhancement observed upon heating above $200{ }^{\circ} \mathrm{C}$ at $2{ }^{\circ} \mathrm{C} / \mathrm{min}$, with respect to the $L$ values found at $40{ }^{\circ} \mathrm{C} / \mathrm{min}$. Preceding synchrotron radiation studies carried out in cold-crystallized PET suggested that a high heating rate favours lamellar melting while the low heating rate promotes thickening of the existing lamellae [23].

In summary, rapid heating cycles are found to inhibit the nanostructural reorganization of the material. Slow heating cycles allow for large nanostructural changes upon heating, involving the melting of the existing crystals and the appearance (or thickening) of new lamellae stacks. This is especially noticeable for $T>200{ }^{\circ} \mathrm{C}$. 


\section{Conclusions}

1. PET samples cold-crystallized at low and at high temperatures are subjected to a nearly continuous structural reorganization upon heating from RT to $260{ }^{\circ} \mathrm{C}$, as revealed by simultaneous WAXS and SAXS analyses.

2. Variations in the degree of crystallinity, crystal size and lamellar periodicity from $T_{\mathrm{g}}$ up to $T_{\mathrm{a}}$ can be explained as due to the melting of thinner and more imperfect lamellae, most probably generated during the cooling process to RT, immediately after cold crystallization at $T_{\mathrm{a}}$.

3. For low- $T_{a}$ and slow heating rates, endotherm I and the subsequent exothermic process observed by means of DSC, starting at $\approx T_{\mathrm{a}}$ and up to $\approx T_{\mathrm{a}}+30^{\circ} \mathrm{C}$, are associated to an incipient melting and recrystallization process, giving rise to new lamellar stacks with slightly larger degree of crystallinity. This melting-recrystallization mechanism is enhanced once $T_{\mathrm{a}}+30{ }^{\circ} \mathrm{C}$ is exceeded (end of the $\alpha$-relaxation process observed for low- $T_{\mathrm{a}}$ materials). Upon heating from $T_{\mathrm{a}}+30{ }^{\circ} \mathrm{C}$ to $200{ }^{\circ} \mathrm{C}$, an extensive structural reorganization takes place, leading to nearly space-filling lamellar stacks and enhanced values of the degree of crystallinity. Finally, endotherm II in the DSC scan initiates at $T \approx 220{ }^{\circ} \mathrm{C}$ and covers the final melting process and the appearance of new lamellar stacks with enhanced crystal size.

4. In contrast, for $h i g h-T_{a}$, the $\alpha_{\mathrm{WAXS}}$ behaviour upon heating at $T>T_{\mathrm{a}}$ is consistent with the occurrence of an increasingly strong melting process. However, the enhanced $D_{100}$ values found above $200{ }^{\circ} \mathrm{C}$ during a slow heating cycle suggest that a recrystallization process also takes place for $200{ }^{\circ} \mathrm{C}<T<250{ }^{\circ} \mathrm{C}$. This temperature range lies within the temperature interval of the DSC endothermic processes I and II observed for $T_{\mathrm{a}}=190{ }^{\circ} \mathrm{C}$ and suggest that, for all $T_{\mathrm{a}}$, recrystallization is an underlaying mechanism always present once $T_{\mathrm{a}}$ is exceeded.

5. The use of a high heating rate hinders the overall material recrystallization process during the heating run. Comparison of slow and rapid heating cycles reveals that slow heating allows for a large nanostructural rearrangement of the material upon heating, involving the melting of the existing crystals and the appearance (or thickening) of new lamellae stacks. Our structural results suggest that the final melting process is shifted to lower temperatures when a high heating rate is employed, in agreement with the DSC measurements. Hence, endotherm II seems to encompass the melting of lamellae generated or thickened during the heating run.

\section{Acknowledgements}

The authors acknowledge the Ministerio de Educación y Ciencia (Grant No. FIS2004-01331), Spain, for the generous support of this investigation. F.J.B.C. also wishes to gratefully acknowledge the Alexander von Humboldt Foundation for the generous support during this work. The experimental work carried out at HASYLAB, DESY, Hamburg, was supported by the European Community - Research Infrastructure Action under the FP6 "Structuring the European Research Area" Programme (project II-04-029 EC). Thanks are also due to SS Funari and M Dommach for their technical support at DESY beamline A2. M.P. gratefully acknowledges MCYT for the award of a sabbatical grant (SAB-2006-0077) to work at IEM, CSIC, Madrid and CNR, Italy, for supporting this initiative within the framework of "Congedi per Motivi di Studio".

\section{References}

[1] Groeninckx G, Reynaers H. J Polym Sci Polym Phys Ed 1980;18:1325. [2] Zhou C, Clough SB. Polym Eng Sci 1988;28:65.

[3] Alfonso GC, Pedemonte E, Ponzetti L. Polymer 1979;20:104.

[4] Baltá Calleja FJ, Baranowska J, Rueda DR, Bayer RK. J Mater Sci 1993;28:6074.

[5] Medellin-Rodriguez FJ, Phillips PJ, Lin JS, Campos R. J Polym Sci Polym Phys 1997;35:1757.

[6] Wang Z-G, Hsiao BS, Sauer BB, Kampert WG. Polymer 1999;40:4615.

[7] Kong Y, Hay JN. Polymer 2003;44:623.

[8] Avila-Orta CA, Medellin-Rodriguez FJ, Wang ZG, NavarroRodriguez D, Hsiao BS, Yeh FJ. Polymer 2003;44:1527.

[9] Minakov AA, Mordvintsev DA, Schick C. Polymer 2004;45:3755.

[10] Wutz C, Bark M, Cronauer J, Döhrmann R, Zachmann HG. Rev Sci Instrum 1995;66:1303.

[11] Verma RK, Hsiao BS. Trends Polym Sci 1996;4:312.

[12] Sauer BB, Kampert WG, Blanchard EN, Threefoot SA, Hsiao BS. Polymer 2000;41:1099.

[13] Marand H, Alizadeh A, Farmer R, Desai R, Velikov V. Macromolecules 2000;33:3392.

[14] Denchev Z, Nogales A, Šics I, Ezquerra TA, Baltá-Calleja FJ. J Polym Sci Polym Phys 2001;39:881.

[15] Santa Cruz C, Stribeck N, Zachmann HG, Baltá Calleja FJ. Macromolecules 1991;24:5980.

[16] Haubruge HG, Jonas AM, Legras R. Macromolecules 2004;37:126.

[17] Baltá Calleja FJ, Vonk CG. X-ray scattering of synthetic polymers. Amsterdam, The Netherlands: Elsevier Science Publishers; 1989.

[18] Lopez Cabarcos E, Gonzalez Arche A, Baltá Calleja FJ, Bösecke P, Röber S, Bark M, et al. Polymer 1991;32:3097.

[19] Stribeck N. X-ray scattering of soft matter. Heidelberg: Springer; 2007.

[20] Stribeck N. Colloid Polym Sci 2002;280:254.

[21] Stribeck N. J Appl Crystallogr 2001;34:496.

[22] Baltá Calleja FJ, Di Marco G, Flores A, Pieruccini M. Phys Rev B 2007;75:224201.

[23] Zachmann HG, Gehrke R. Advances in indirect methods of polymer morphology characterization. In: Sedláček B, editor. Morphology of polymers. Berlin: Walter de Gruyter and Co.; 1986. 